life. Obesity is considered to be associated with the incidence and progression of $\mathrm{OA}$, thus weight loss is of paramount importance in OA management.

Objectives: To evaluate the efficacy of pharmacological and non-pharmacological therapy of obesity in pts with knee OA.

Methods: The study included 50 female pts aged 45-65 years with knee OA, Kellgren-Lawrence stage II-III, and obesity $\left(\mathrm{BMI}>30 \mathrm{~kg} / / \mathrm{m}^{2}\right)$. Pts form Group 1 $(n=25)$ were administered orlistat at $120 \mathrm{mg} \times 3$ times a day for 6 month alongside with low-caloric diet and therapeutic physical exercise. Pts from Group $2(n=25)$ adhered to life-modifying therapy only, i.e. low-caloric diet and therapeutic physical exercise for 6 month. Anthropometry data (height, body weight, BMI), as well as WOMAC and quality of life EQ-5D scores were assessed at baseline, at 6 and 12 months (i.e, 6 months after discontinuation of therapy) after initiation of treatment in all pts.

Results: After 6 months of pharmacological therapy pts from Group 1 achieved significant mean weight loss by $10,07 \%(p<0,05)$, while pts from Group 2 with non-pharmacological therapy demonstrated only $<1 \%(0,84 \%) \quad(p>0,05)$ weight loss. Pts receiving pharmacological therapy with orlistat demonstrated the following improvements by WOMAC subscales: pain reduction by $52,5 \%(p<0,05)$, stiffness reduction by $47,98 \%(p<0,05)$, and $51,55 \%$ function improvement, while total WOMAC score improved by $51,49 \%(p<0,05)$. Respective WOMAC subscale scores in pts from Group 2 were considerably less impressive vs Group 1. Pts from Group 1 demonstrated statistically significant improvement in the quality of life by $52,27 \%$ EQ-5D $(p<0,05)$. EQ-5D score remained unchanged only in 2 pts from Group 1 who failed to lose weight. During the following 6 months after discontinuation of orlistat pts from Group 1 regained 5,6\% of their body weight $(p<0,05)$ (Fig.1), which was associated with OA worsening OA (deterioration of pain by $42,63 \%(p<0,05)$ WOMAC, and total WOMAC score decrease by $23,15 \%)$. After 12 months of follow up pts from Group 2 showed body weight loss by $3,5 \%$, and continuing decrease of pain in knee joints by WOMAC pain subscale, reaching $22,3 \%(p<0,05)$ as compared to baseline.

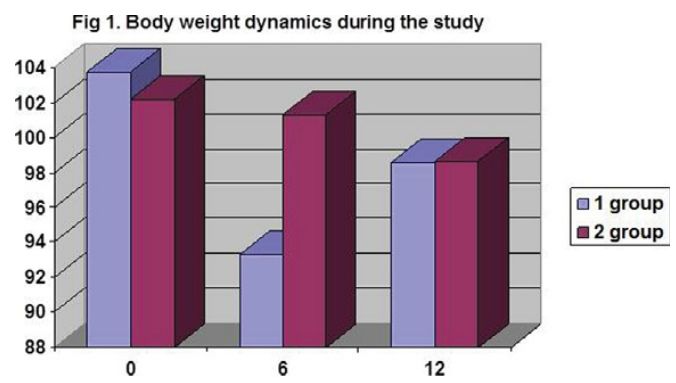

Conclusions: The results of our study demonstrate significant $>10 \%$ weight loss in OA pts induced by orlistat therapy. Such a noticeable weight loss was associated with reduced pain intensity, improved function and quality of life in OA pts. Partial regain of body weight during 6 months after discontinuation of orlistat was accompanied by worsening of OA clinical course. Thus, effective maintenance of optimal body weight in OA pts requires longer pharmacotherapy of obesity.

Disclosure of Interest: None declared

DOI: 10.1136/annrheumdis-2017-eular.2819

\section{SAT0511 THUMB BASE OSTEOARTHRITIS: ASSOCIATIONS BETWEEN SYNOVITIS ON ULTRASOUND AND PAIN}

S. Ermurat ${ }^{1}$, F. Kroon ${ }^{2}$, M. Kortekaas ${ }^{2}$, M. Reijnierse ${ }^{3}$, M. Kloppenburg ${ }^{2,4}$. ${ }^{1}$ Rheumatology, Uludag University Medical Faculty, Bursa, Turkey;

${ }^{2}$ Rheumatology; ${ }^{3}$ Radiology; ${ }^{4}$ Clinical Epidemiology, Leiden University Medical Center, Leiden, Netherlands

Background: Hand osteoarthritis (OA) affects the interphalangeal (IP) joints but also the first carpometacarpal (CMC1) joint in the thumb base. Previous ultrasonography (US) studies of the IP joints have shown that inflammatory and structural features are frequently present and associated with clinical signs and symptoms. Until now, US studies specifically assessing the CMC1 joint have not been performed.

Objectives: To investigate associations between inflammatory features, structural damage and pain in $\mathrm{CMC} 1 \mathrm{OA}$

Methods: Cross-sectional data of 87 hand OA patients participating in the EChography in Hand OA $(n=63)$ and the Etanercept in Hand OA $(n=24)$ study at the Leiden University Medical Center were used in this analysis. Both CMC1 joints were assessed with US for synovial thickening, effusion and power Doppler signal (PDS) on a $0-3$ scale by experienced ultrasonographers. Presence of pain upon palpation of the thumb base was assessed by trained research nurses on the same day as the US. Hand radiographs were scored blinded for clinical and US features, according to the Osteoarthritis Research Society International atlas for osteophytes (0-3), joint space narrowing (JSN, 0-3), sclerosis $(0-1)$ and malalignment $(0-1)$ in the CMC1 joint. Risk ratios (RRs) with $95 \%$ confidence intervals (Cls) were calculated using generalized estimating equations to investigate associations between US or radiographic features and thumb base pain on joint level.
Results: Of 87 patients (mean age 60.3 years, $82 \%$ women, mean BMI 27.2 $\mathrm{kg} / \mathrm{m}^{2}$ ) $174 \mathrm{CMC} 1$ joints were assessed, of which $54(31 \%)$ were painful. The US features synovial thickening, effusion and PDS were found in $26 \%, 33 \%$ and $25 \%$ of the joints, respectively. Radiographic features were present in $55 \%$ (osteophytes), $79 \%$ (JSN), 20\% (sclerosis) and 12\% (malalignment) of the joints. No associations were seen between inflammatory US features and pain upon palpation of the thumb base (Table). However, osteophytes and sclerosis were associated with more pain (RR 2.5 [95\% Cl 1.4 to 4.6$]$ for osteophytes grade 3 versus no osteophytes, and RR 2.0 [95\% $\mathrm{Cl} 1.3$ to 3.2$]$ for presence of sclerosis). Other radiographic features (JSN, malalignment) showed a trend for increased risk of pain on palpation, and for osteophytes and JSN a dose-response relation was apparent.

Table. Associations of US and radiographic features with pain on palpation in thumb base $O A(n=171$ joints*)

\begin{tabular}{|c|c|c|}
\hline & Tenderness yes/no, $\mathbf{n}$ & RR (95\% Cl) \\
\hline \multicolumn{3}{|c|}{ US features } \\
\hline \multicolumn{3}{|c|}{ Synovial thickening } \\
\hline Absent & $40 / 85$ & 1 \\
\hline Grade 1 & $10 / 22$ & $1.1(0.6-1.8)$ \\
\hline Grade $2 / 3$ & $4 / 10$ & $0.9(0.4-2.4)$ \\
\hline \multicolumn{3}{|l|}{ Effusion } \\
\hline Absent & $35 / 79$ & 1 \\
\hline Grade 1 & $13 / 25$ & $0.8(0.4-1.5)$ \\
\hline Grade $2 / 3$ & $6 / 13$ & $0.8(0.3-2.0)$ \\
\hline \multicolumn{3}{|c|}{ Power doppler signal } \\
\hline Absent & $41 / 86$ & 1 \\
\hline Grade 1 & $8 / 24$ & $0.9(0.5-1.6)$ \\
\hline Grade $2 / 3$ & $5 / 7$ & $1.2(0.7-2.0)$ \\
\hline \multicolumn{3}{|c|}{ Radiographic features } \\
\hline \multicolumn{3}{|c|}{ Osteophytes } \\
\hline Absent & $18 / 58$ & 1 \\
\hline Grade 1 & $16 / 40$ & $1.2(0.7-2.2)$ \\
\hline Grade 2 & $11 / 13$ & $1.5(0.7-2.9)$ \\
\hline Grade 3 & $9 / 6$ & $2.5(1.4-4.6)$ \\
\hline \multicolumn{3}{|c|}{ Joint space narrowing } \\
\hline Absent & $8 / 27$ & 1 \\
\hline Grade 1 & $36 / 77$ & $1.6(0.8-3.3)$ \\
\hline Grade 2 & $7 / 9$ & $2.1(0.8-5.3)$ \\
\hline Grade 3 & $3 / 4$ & $2.5(0.9-7.0)$ \\
\hline \multicolumn{3}{|l|}{ Sclerosis } \\
\hline Absent & $38 / 104$ & 1 \\
\hline Present & $16 / 13$ & $2.0(1.3-3.2)$ \\
\hline \multicolumn{3}{|l|}{ Malalignment } \\
\hline Absent & $44 / 107$ & 1 \\
\hline Present & $10 / 10$ & $1.4(0.7-2.7)$ \\
\hline
\end{tabular}

number; $\mathrm{OA}$, osteoarthritis; $\mathrm{RR}$, risk ratio; US, ultrasound.

Conclusions: Radiographic features, especially osteophytes and JSN, were prevalent and more frequently present than US inflammatory features in the CMC1 joints of hand OA patients. In contrast to what is known from studies in IP joints, the presence of inflammatory US features was not associated with pain in the thumb base, but structural damage was. These results suggest differences in etiology of pain in thumb base compared to IP OA, with a larger role for structural damage in thumb base OA.

Disclosure of Interest: None declared

DOI: 10.1136/annrheumdis-2017-eular.4921

\section{SAT0512 MRI PROVIDING INSIGHTS IN ASSOCIATION OF SYNOVITIS AND BONE MARROW LESIONS (BMLS) WITH PAIN IN THUMB BASE OSTEOARTHRITIS (OA)}

F. Kroon ${ }^{1}$, S. van Beest ${ }^{1}$, W. Damman ${ }^{1}$, R. Liu ${ }^{1}$, M. Reijnierse ${ }^{2}$, M. Kloppenburg $1,3 .{ }^{1}$ Rheumatology; ${ }^{2}$ Radiology; ${ }^{3}$ Clinical Epidemiology, Leiden University Medical Center, Leiden, Netherlands

Background: Hand $\mathrm{OA}$ affects the interphalangeal (IP) and thumb base joints (first carpometacarpal [CMC1] and scaphotrapeziotrapezoid [STT]). Much is still unknown about the pathophysiology of thumb base OA. Magnetic resonance imaging (MRI) studies have led to new insights in IP OA, but in absence of a scoring system thumb base MRI studies are lacking.

Objectives: Investigate the prevalence of MRI synovitis and BMLs in the thumb base, and their association with pain, using the novel OMERACT thumb base OA MRI scoring system (TOMS) ${ }^{1}$

Methods: Cross-sectional data of the Hand OSTeoArthritis in Secondary care (HOSTAS) study, including consecutive patients diagnosed by their treating rheumatologist with primary hand OA, were used. Patients with an MRI of the right thumb base at baseline were included in the analysis. MRIs were scored by two readers using the TOMS for synovitis and bone marrow lesions (BMLs) in the CMC1 and STT joints (grade $0-3$ ). BMLs were evaluated in the proximal and distal joint parts separately, resulting in a 0-6 and 0-9 sum score for CMC1 and STT, respectively. Pain on palpation of the thumb base was assessed by trained research nurses. Hand radiographs were assessed for presence of osteophytes in the CMC1 and STT joints. Associations between MRI lesions and thumb base tenderness were analysed using logistic regression, presented as odds ratios (ORs) with $95 \%$ confidence intervals $(\mathrm{Cls})$, stratified for absence or presence of radiographic osteophytes. For the analyses synovitis and BML scores were 
aggregated into a dichotomous total thumb base involvement score (0-1 in both joints vs $\geq 2$ in at least one joint).

Results: 85 out of 202 patients ( $84 \%$ women, mean age 60.1 years) reported pain on palpation in the thumb base. Synovitis was seen in both thumb base joints (CMC1 42\%, STT 37\%), although prevalence of grade 2-3 synovitis was low in both the CMC1 (16\%) and STT (14\%). BMLs were present in CMC1 and STT in 54 and $53 \%$, respectively, with 18 and $21 \%$ having a sum score of $2-3$, and 16 and $7 \%$ a sum score $\geq 4$. In absence of radiographic osteophytes, presence of synovitis or BMLs in either thumb base joint was not statistically significantly associated with thumb base tenderness (ORs 1.9 [95\% $\mathrm{Cl} 0.6-6.4]$ and 1.5 [0.5-4.3], respectively). However, in absence of synovitis or BMLs, radiographic osteophytes and pain were associated, with increasing ORs when MRI lesions were additionally present (Table). Similar results were found for self-reported thumb base pain (not shown)

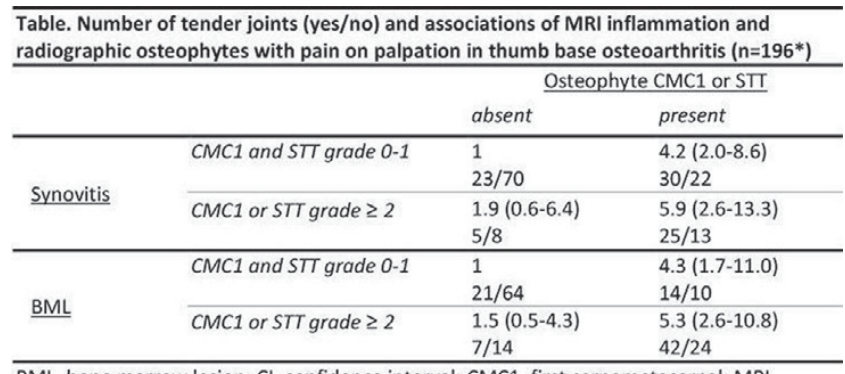

$\mathrm{BML}$, bone marrow lesion; $\mathrm{Cl}$, confidence interval; $\mathrm{CMC1}$, first carpometacarpal; MRI, magnetic resonance imaging; OR, odds ratio; STT, scaphotrapeziotrapezoid.

${ }^{*} n=196$ patients with available radiographs and evaluable MRI for synovitis and BMLs.

Conclusions: Synovitis and BMLs are present in the thumb base, although severe MRI lesions were uncommon. Prevalence of synovitis was similar in the CMC1 and STT joints, although higher BML scores were more frequently seen in CMC1. Radiographic osteophytes seemed more important in predicting thumb base tenderness than MRI inflammation alone. Combined presence of radiographic osteophytes and $M R I$ lesions had a small additive effect. These findings are in contrast to results from IP OA studies, supporting thumb base $\mathrm{OA}$ as a distinct hand $\mathrm{OA}$ subset. It might also explain why trials investigating intra-articular corticosteroids in thumb base OA have led to equivocal results.

References:

[1] Kroon F, Conaghan P, Foltz V, et al. J Rheumatol 2017 (in press).

Disclosure of Interest: None declared

DOI: 10.1136/annrheumdis-2017-eular.2879

\section{SAT0513 FUNCTIONAL IMPAIRMENT RATHER THAN BURDEN OF CO-MORBIDITIES IS ASSOCIATED WITH A 5-YEAR CHANGE IN HEALTH STATE UTILITY IN HIP AND KNEE OSTEOARTHRITIS: RESULTS FROM THE KHOALA COHORT STUDY}

A.Y. Omorou ${ }^{1,2}$, H. Achit $^{2}$, M. Wieczorek ${ }^{1}$, B. Fautrel ${ }^{3}$, A.-C. Rat ${ }^{1}$, F. Guillemin ${ }^{1,2}$. ${ }^{1}$ Ea 4360 Apemac, University of Lorraine; ${ }^{2} \mathrm{CIC}-1433$ Clinical Epidemiology, CHRU Nancy, Nancy; ${ }^{3}$ UPMC Université Paris 6, Grc-Upmc 08 (Eemois), Sorbonne Universités, Paris, France

Background: Functional impairment of hip and knee osteoarthritis (OA) and associated co-morbidities can independently impact patient's health state utility (HSU), a useful indicator for valuing health in medico-economic studies.

Objectives: This study aimed to examine the respective influence of the evolution of functional impairment and of burden of co-morbidities on a 5-year change in HSU for patients with OA.

Methods: 548 patients (Mean age of 61.1 years, $66.6 \%$ of women and $68.1 \%$ with knee OA) from the KHOALA study with 5 years follow-up were included. Functional impairment, co-morbidities and HSU were measured annually using the WOMAC (0-100) [1], FCl (1-18) [2] and SF-6D (0-1) [3], respectively. First, baseline clinical patterns were identified using hierarchical clustering methods [4]. Then, the role of these patterns as determinants of 5-year change in HSU was analysed using hierarchical mixed models.

Results: Two clusters were identified: cluster 1 "Low functional impairment and few co-morbidities" (65.3\%) and cluster 2 "Severe functional impairment and many co-morbidities" (34.7\%). Compared to the cluster 1, the functional impairment of cluster 2 significantly decreased $(-14.5[-18.1 ;-10.92])$ at 5 year follow up, while the co-morbidity index significantly increased in the two clusters $(+0.18[-0.22$; 0.57]). The mean baseline HSU score was 0.66 ( 0.70 for cluster 1 and 0.59 for cluster 2). Compared to cluster 1, patients in cluster 2 had a significantly higher increased in 5-year HSU $\left(\beta=+0.0335\right.$ [0.0088; 0.0583]) $\left(R^{2}=21 \%\right)$. The difference of 5 -year change in HSU was no more significant when adjusted for change in functional impairment $(\beta=+0.0335 ; p=0.008$ vs. $-0.0153 ; p=0.30)\left(R^{2}=42 \%\right)$ while it remained significant when adjusted for change in co-morbidity index $(\beta=+0.0335$; $p=0.008$ vs. $+0.0386 ; p=0.002)\left(R^{2}=27 \%\right)$.

Conclusions: Cluster analysis showed that patients with severe functional impairment also had high rate of co-morbidities à baseline. The reduction of OA functional impairment is an important determinant of 5-year improvement of HSU while burden of co-morbidities was not associated with change in hip and knee $\mathrm{OA} \mathrm{HSU}$. This result highlights the importance of reducing functional impairment in clinical management of patients with hip and knee OA, and gives clues for interpretation of medico-economic analyses.

References:

[1] Bellamy N, Buchanan WW, Goldsmith $\mathrm{CH}$, Campbell J, Stitt LW. Validation study of WOMAC: a health status instrument for measuring clinically important patient relevant outcomes to antirheumatic drug therapy in patients with osteoarthritis of the hip or knee. J. Rheumatol. 1988;15:1833-40.

[2] Groll DL, To T, Bombardier C, Wright JG. The development of a comorbidity index with physical function as the outcome. J. Clin. Epidemiol. 2005;58:595602

[3] Brazier J, Usherwood T, Harper R, Thomas K. Deriving a preferencebased single index from the UK SF-36 Health Survey. J. Clin. Epidemiol. 1998:51:1115-28.

[4] Everitt BS. Unresolved Problems in Cluster Analysis. Biometrics. 1979;35:169.

Disclosure of Interest: None declared

DOI: 10.1136/annrheumdis-2017-eular.3796

\section{SAT0514 CAN IMMUNOPHENOTYPING OF SYNOVIAL FLUID CELLS HELP DISTINGUISH BETWEEN PATIENTS WITH OSTEOARTHRITIS?}

G. Gabcova ${ }^{1}$, G. Manukyan ${ }^{2}$, Z. Mikulkova ${ }^{1}$, E. Kriegová ${ }^{1}$, J. Gallo $^{3}$. ${ }^{1}$ Department of Immunology, Faculty of Medicine and Dentistry, Palacky University, Olomouc, Czech Republic; ${ }^{2}$ Group of Molecular and Cellular Immunology, Institute of Molecular Biology NAS RA, Yerevan, Armenia; ${ }^{3}$ Department of Orthopaedics, Palacky University, Teaching Hospital Olomouc, Olomouc, Czech Republic

Background: Osteoarthritis $(\mathrm{OA})$ is a leading cause of chronic pain and functional disability in elder people. It is not a homogeneous but diverse group of synovial joint diseases. This could stay behind the therapeutic inconsistency observed in clinical practice caused probably by different diseases and/or different stages of a single disease. The comprehensive immunophenotyping of immune cells and their cell counts in synovial fluid (SF) might therefore advance our understanding of a particular type/stage of OA. This could have diagnostic value as well as provide novel insights into the pathophysiology of OA.

Objectives: To characterize immune cells present in SFs from OA patients in different stages of a disease.

Methods: We performed immunophenotyping of SFs from 63 patients with $\mathrm{OA}$ and $10 \mathrm{SFs}$ from control patients (non-OA) without clinical/radiographic signs of $\mathrm{OA}$ using flow cytometry. We were able to characterize the following immune cells in the sampled SFs: T helper lymphocytes $\left(\mathrm{CD}^{+} / \mathrm{CD} 4^{+}\right), \mathrm{T}$ cytotoxic lymphocytes $\left(\mathrm{CD}^{+} / \mathrm{CD}^{+}\right)$, NK cells $\left(\mathrm{CD}^{-} / \mathrm{CD} 16^{+} / \mathrm{CD}^{+} 6^{+}\right)$, B lymphocytes $\left(\mathrm{CD} 19^{+}\right)$, $\mathrm{T}$ regulatory (Treg) cells $\left(\mathrm{CD}^{+} / \mathrm{CD}^{2} 5^{+} / \mathrm{CD} 127^{-}\right)$, mast

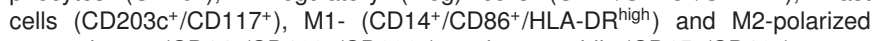
macrophages $\left(\mathrm{CD} 14^{+} / \mathrm{CD} 163^{+} / \mathrm{CD} 206^{+}\right)$, and neutrophils $\left(\mathrm{CD} 15^{+} / \mathrm{CD} 16^{+}\right)$.

Results: A comparison between $\mathrm{OA}$ and control (non-OA) SFs revealed phenotypic alterations mainly in T cells, NK cells, macrophages, and neutrophils. $\mathrm{T}$ cells were the predominant population in the SFs, with $\mathrm{CD}^{+}{ }^{+} \mathrm{T}$ lymphocytes being more prevalent than $\mathrm{CD}^{+} \mathrm{T}$ cells in $\mathrm{OA}$ (increased $\mathrm{CD} 4 / \mathrm{CD} 8$ ratio). The second largest cell population was macrophages. Despite the dominant mixed-polarized (M1-M2) macrophage subpopulations in both the studied groups, SFs from the OA patients displayed a tendency towards greater M1 activity comparing to the controls. A markedly increased percentage of neutrophils found in the OA group was associated with their activated state compared to the controls (increased CD11b). No difference was found in percentages of B, Treg and mast cells. Despite the similar numbers of NK cells in both the groups, the activation-associated marker CD69 was up-regulated in NK cells from the OA patients. Representative dot-plots (FCS-SSC) of inter-individual variability of the main immune cell populations in synovial fluids from osteoarthritic patients is shown in Figure 1.
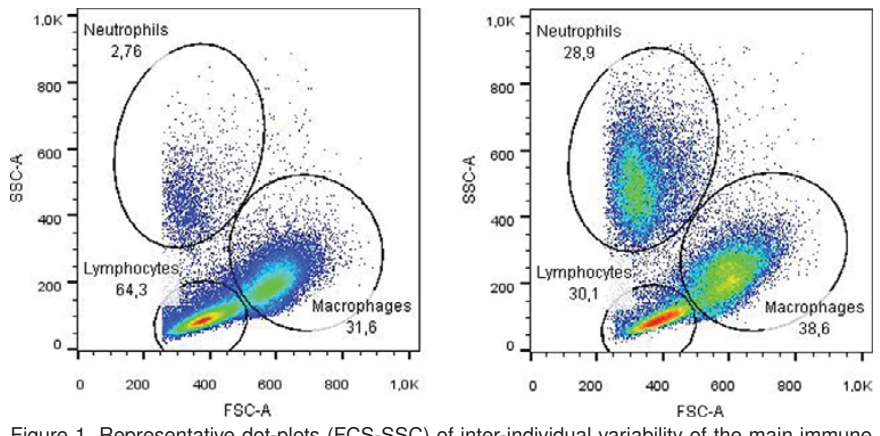

Figure 1. Representative dot-plots (FCS-SSC) of inter-individual variability of the main immune cell populations in synovial fluids from osteoarthritic patients.

Conclusions: We were able to distinguish between the OA cases and controls 